\section{Fresh strategies to save orangutans}

The Bornean orangutan (Pongo pygmaeus) was listed as critically endangered by the International Union for Conservation of Nature this month, despite decades of conservation efforts. We urgently need fresh strategies to counteract habitat loss and hunting, and to mitigate the impacts of climate change.

Both species of Asia's only great ape (P.pygmaeus and the Sumatran orangutan, P. abelii) now face 'an extremely high risk of extinction' Safeguarding protected areas and enforcing existing bans on orangutan killing are still important, but such efforts are insufficient in isolation (E. Meijaard et al. Ann. N. Y. Acad. Sci. 1249, 29-44; 2012).

We need to maximize the conservation value of degraded lands and use an integrated, landscape-scale approach to reconcile economic development and biodiversity conservation. And we must promote sustainable management practices that are backed by rigorous, transparent certification mechanisms and that incorporate explicit economic valuation of the ecosystem services provided by orangutans and their habitats.

Crucially, success will also demand direct engagement and collaboration between conservationists and the mining, forestry and oil-palm industries. Andrew J. Marshall University of Michigan, Ann Arbor, USA. Serge Wich Liverpool John Moores University, UK. Marc Ancrenaz Borneo Futures, Kota Kinabalu, Sabah, Malaysia. ajmarsha@umich.edu

\section{Vet reproducibility of biology preprints}

Posting preprints in online repositories is common practice in the physical sciences and mathematics. It has been less satisfactory for preprints in the biological sciences, perhaps because the general standard of quality is inferior. Addressing the credibility of these submissions could bring free preprint servers such as bioRxiv (founded in 2013; bioRxiv.org) more into line with arXiv (arxiv.org), which has been running successfully for 25 years.

Introducing a staging process for submission could rectify the credibility problem. This would establish priority for new work and allow time for it to earn a seal of approval - thereby helping to speed publication after formal submission to a journal.

Initially, an abstract would be assessed by the editors of the preprint server to confirm suitability for posting. Submission of a short form of the paper would follow, with added details of raw data, materials and methods; this would allow other researchers to confirm, refute or comment on the results. After 6 months, the authors could submit a revised preprint in response to this feedback, together with evidence to support the paper's credibility and reproducibility; alternatively, they could withdraw the manuscript with dignity. Roy Calne University of Cambridge, UK. ryc1000@medschl.cam.ac.uk

\section{SDGs: diseases that neglect no goals}

The mapping of interactions between the United Nations' Sustainable Development Goals (SDGs) should guide efforts to leave no one behind (see M. Nilsson et al. Nature 534, 320-322; 2016).

Take neglected tropical diseases (NTDs; go.nature.com/29te2hu) and the SDG target to end epidemics by 2030 . Doing so will have a positive interaction with all SDGs, including those directed at poverty, hunger, education, work, growth and inequality (C. Fitzpatrick and D. Engels Intl Health 8 (S1), i15-i18; 2016). The example set by the largest-ever ongoing donation of medicines from drug firms (see go.nature. com/2ag1gnf) will help to realize the public-private partnership goal for health.

Community-led distribution of those medicines to more than 1 billion at-risk people is reinforcing other goals, such as women's empowerment, logistics infrastructure and non-discrimination against disability. Curbing mosquitoborne NTDs contributes to the goals of urban sustainability and resilience to climate change. Safe use of insecticides supports the goal of sustainable ecosystems. Controlling water- and animalrelated NTDs is facilitating the goals of small-scale fishing and sustainable hydroelectricity and biofuels.

The World Health Organization is monitoring some of the most important positive interactions. For example, we are using NTDs to highlight inequalities, to target investment and to track progress towards universal access to water, sanitation and hygiene (see go.nature.com/29tpeph). Christopher Fitzpatrick, Mathieu Bangert, Dirk Engels WHO, Geneva, Switzerland. fitzpatrickc@who.int

\section{SDGs: create a coordinating body}

The United Nations' Sustainable Development Goals (SDGs) seem to be a disjointed hodge-podge of aspirations. I suggest that a panel of panels' would help to guide policymakers. This would collate the flow of information from existing UN panels to highlight connections between the SDGs (see also M. Nilsson et al. Nature 534, 320-322; 2016).

This meta-panel could be modelled on international science platforms that coordinate multilateral environmental governance regimes, such as those for climate and biodiversity (see also P. M. Haas and C. Stevens in Governing the Air (eds R. Lidskog and G. Sundqvist) 125-161; MIT Press, 2011). It would similarly comprise independent experts from various countries and disciplines, drawn from academia, civil society and the private sector to capture different perspectives on sustainability.

The panel should be properly funded and not depend on a single funding source. It would meet regularly and report directly to governments through the UN High Level Political Forum. Its findings would need to be especially clear in areas of consensus and controversy. Peter M. Haas University of Massachusetts Amherst, USA. haas@polsci.umass.edu

\section{A very preventable mammal extinction}

James Watson blames climate change for the extinction of the Bramble Cay melomys, or mosaic-tailed rat (Melomys rubicola; Nature 534, 437; 2016). In our view, simple management interventions could and should have saved this rodent.

With a population of at most a few hundred and a range limited to a single, small island (less than 5 hectares) that is susceptible to inundation in storm surges, the melomys was already living on the brink of extinction. Yet not an iota of effort was made, or resources committed, to reduce its extreme vulnerability.

Perhaps because the species lacked phylogenetic, cultural or ecological significance, responsible agencies seemed to treat it as inconsequential. A recovery plan developed in 2008 did not include plausible options for captive breeding or for translocation to nearby islands, and was never implemented.

Neglect and inaction caused this extinction - climate change was one of many threats that could have delivered the final blow. Such disregard must not be allowed to drive more extinctions. John C. Z. Woinarski ${ }^{\star}$ Threatened Species Recovery Hub, Australia. john.woinarski@cdu.edu.au ${ }^{\star}$ On behalf of 4 correspondents (see go.nature.com/2aelgaj for full list). 